CLINICAL STUDY

\title{
Reduced quality of life in patients with head-and-neck paragangliomas
}

\author{
B Havekes, A A van der Klaauw, H C Hoftijzer, J C Jansen ${ }^{1}$, A G L van der Mey ${ }^{1}$, A H J T Vriends ${ }^{2}$, J W A Smit, \\ J A Romijn and E P M Corssmit \\ Department of Endocrinology and Metabolic Diseases, Leiden University Medical Center, PO Box 9600, 2300 RC Leiden, The Netherlands, ${ }^{1}$ Department of \\ Otorhinolaryngology and ${ }^{2}$ Center of Human and Clinical Genetics, Leiden University Medical Center, Leiden, The Netherlands \\ (Correspondence should be addressed to B Havekes; Email: b.havekes@lumc.nl)
}

\begin{abstract}
Objective: The objective of this study was to assess the quality of life (QoL) in patients with head-and-neck paragangliomas ('glomus tumors').

Design: We conducted a case-control study.

Methods: We assessed QoL in 82 patients with head-and-neck paragangliomas using four validated healthrelated questionnaires: Hospital Anxiety and Depression Scale, Multidimensional Fatigue Index (MFI-20), Short Form-36 (SF-36), and Nottingham Health Profile (NHP). Patient outcomes were compared with controls provided by the patients and with a large age- and sex-adjusted control group.

Results: The QoL scores in the paraganglioma patients were significantly reduced in 12 out of the 21 subscales compared with own controls, and in 18 out of the 21 subscales compared with age- and sexadjusted values derived from the previous studies. In the MFI-20 questionnaire, patients reported more general fatigue, physical fatigue, mental fatigue, and a reduction in activity and motivation. The scores in the NHP showed a difference in energy, emotional reaction, and social isolation. General health perception, pain, and physical functioning were reported to be worse in the paraganglioma patients on the SF- 36 scale. Although anxiety and depression did not reveal any significant differences between patients and their own controls, an increased score on both anxiety and depression was seen when compared with the extended control group. Especially, dysphonia contributes to a reduced QoL.

Conclusion: QoL is considerably reduced in patients with head-and-neck paragangliomas.
\end{abstract}

European Journal of Endocrinology 158 247-253

\section{Introduction}

Paragangliomas are frequently multifocal tumors arising from the neural crest cells associated with the autonomic nervous system. Traditionally, they are divided into headand-neck paragangliomas (also referred to as 'glomus tumors') and paragangliomas located in the thorax and abdomen. Some paragangliomas produce excessive amounts of catecholamines, especially if they are located in the adrenals (pheochromocytoma). Familial paraganglioma syndromes are associated with germ line mutations in the genes encoding subunits of mitochondrial complex II succinate dehydrogenase (SDH): SDHD, SDHC, and SDHB (1-6). These SDH genes can behave as tumor suppressor genes and distinct genotypephenotype relations have been described (1, 5, 7-9). Among these three genes, mutations in SDHD are the most frequent cause of familial head-and-neck paragangliomas in the Netherlands $(1,9,10)$.

Head-and-neck paragangliomas are usually benign tumors, but their location in close proximity to nerves and vasculature in the head-and-neck region often results in considerable morbidity. Patients often complain about hearing loss, hoarseness, and problems in swallowing. The choice between a wait-and-see policy and surgical removal of the tumor can be rather difficult because surgery itself can result in additional loss of nerve function. In addition, the need for patients with familial paraganglioma to remain under lifelong surveillance could have major implications for their general sense of well-being (11).

Although it can thus be hypothesized that head-andneck paragangliomas affect quality of life (QoL), so far no studies on QoL in the head-and-neck paraganglioma patients compared with the healthy controls have been published. In the present study, the aim was to assess QoL in the head-and-neck paraganglioma patients using four validated health-related QoL questionnaires. Patient outcomes of QoL parameters were compared with those of control subjects as well as with age- and sex-adjusted reference values derived from the previous studies performed in Leiden (12-16). 


\section{Patients and methods}

\section{Study protocol}

Patients were recruited from the outpatient clinic of the Department of Endocrinology of the Leiden University Medical Center, which is a tertiary referral center for paragangliomas. All patients are being followed up according to a standardized protocol. They are seen at least every 2 years with repetitive head-and-neck magnetic resonance imaging (MRI) to follow growth and development of other paragangliomas. Urine is collected over $24 \mathrm{~h}$ in duplicate under strict dietary regulations and after stopping medication for several weeks or changing antihypertensive medication to doxazosine. In the case of excessive catecholamine secretion, MIBG scanning and additional MRI imaging of the abdomen and/or thorax are performed to identify the source of catecholamine overproduction. All patient data regarding clinical, biochemical, and radiological investigations are recorded in a database. In this study, we used 105 consecutive patients with one or more head-and-neck paragangliomas, with or without (a history of) paragangliomas at other locations, who had been referred to our outpatient clinic for screening purposes.

A total of 105 consecutive patients with head-and-neck paragangliomas were asked to participate in this study. Patients received four validated QoL questionnaires in prepaid envelopes. Patient records were scrutinized for patient history, concomitant morbidity, medication, and physical examination. Furthermore, to complete clinical data, patients were sent a list of questions focusing on complaints possibly due to head-and-neck paragangliomas. Non-responders were encouraged by phone to complete and return the questionnaires by post. We systematically recorded data regarding all biochemical, radiological, and genetic investigations that had been (repetitively) performed on these patients in the past. Each patient was also asked to provide a control person of comparable age and sex with a comparable socioeconomic status from the same geographical area. In addition, to control for potential bias introduced by the selection of controls by the patients, we also used a larger cohort of age- and sex-matched control subjects who were derived from other studies in our center and who had been similarly approached (12-16). For every head-and-neck paraganglioma patient, two additional sex- and age-matched control subjects were selected. The Medical Ethics Committee of the Leiden University Medical Center approved the study protocol.

\section{Study parameters}

Primary study parameters were the outcomes of the four health-related QoL questionnaires. The relationship between these outcomes and characteristics (age and gender) of the patients, number and location of head-and-neck paragangliomas, surgical procedures, biochemical data, and clinical data was investigated.

\section{QoL questionnaires}

Hospital Anxiety and Depression Scale (HADS) The HADS consists of 14 items pertaining to anxiety and depression. Each item is measured on a 4-point scale. Scores for the anxiety and depression subscale range from 0 to 21 , and for the total score from 0 to 42 . A higher score reflects more severe anxiety and depression (17). A total score of 13 or more was considered increased.

Multidimensional Fatigue Index (MFI-20) The MFI-20 contains 20 statements to assess fatigue (18). Five different dimensions of fatigue (four items each) are calculated from these statements: 1) general fatigue, 2) physical fatigue, 3) reduced activity, 4) reduced motivation, and 5) mental fatigue. Every statement is measured on a 5-point scale; scores vary between 0 and 20. Higher scores correlate with a higher feeling of fatigue.

Nottingham Health Profile (NHP) The NHP survey consists of 38 yes/no questions. These are subdivided into six scales assessing impairments: pain (eight items), energy level (three items), sleep (five items), emotional reactions (nine items), social isolation (five items), and disability/functioning (eight items) $(19,20)$. Subscale scores are calculated as a weighted mean of the associated items and are expressed as a value ranging from 0 to 100 . The total score is the mean of the six subscales. A high score points to a worse QoL.

Short Form-36 (SF-36) The SF-36 questionnaire has 36 items assessing general well-being during the previous 30 days $(21,22)$. The items are formulated as statements or questions to assess eight health concepts: 1) physical functioning, 2) social functioning, 3) limitations in usual role activities because of physical health problems, 4) pain, 5) general mental health (psychological distress and well-being), 6) limitations in usual role activities because of emotional problems, 7) vitality (energy and fatigue), and 8) general health perceptions and change in health. Scores are expressed on a 0-100 scale, in which higher scores are associated with a better QoL.

\section{DNA analysis}

Prior to germ line mutation testing, informed consent was obtained from each patient. DNA was screened for germ line mutations by restriction digestion, as described by Taschner et al. (10).

\section{Statistical analysis}

SPSS for Windows version 12.0 (SPSS Inc., Chicago, IL, USA) was used for data analysis. Data are expressed as mean \pm s.D., unless otherwise mentioned. We used unpaired $t$-tests to compare patient and control data. 
One-way ANOVA or unpaired sample $t$-tests were used to compare several subgroups of patients, when appropriate. Independent variables affecting QoL were assessed by linear regression analysis. These results were expressed as the absolute standardized $\beta$ of independent predictive values. $P<0.05$ was considered significant.

\section{Results}

\section{Patient and treatment characteristics}

In total, 82 out of the 105 patients (78\%) returned the completed questionnaires. Mean age was $47 \pm 12$ years. No significant differences in age, gender, and number of paragangliomas were found between the study population and the patients who did not return the questionnaires. All the 82 patients who returned the questionnaires, provided 44 controls (53\%).

There were no significant differences in age and sex between patients and controls (Table 1). The matched control group derived from the previous studies showed a similar distribution of age and sex. Out of the paraganglioma patients, $40 \%$ had one glomus tumor, $27 \%$ had two glomus tumors, whereas 33\% were diagnosed with three or more tumors. Carotid body tumors were most frequently found, nearly half of which had been operated at some point during follow-up. In total, 14 patients were diagnosed with past or present intra-adrenal paragangliomas $(17 \%)$, and in 3 patients an extra-adrenal paraganglioma had been identified.

The following complaints were registered: patients had both local complaints and hearing loss in 39\% of the cases, tinnitus was present in $37 \%$, hoarseness was found in $21 \%$, and difficulties in swallowing were found in $26 \%$ of the patients.
Genetic analysis had been performed in 69 out of the 105 patients $(66 \%)$. In 58 of these patients, an SDHD (D92Y) mutation was found (84\%).

\section{QoL in head-and-neck paraganglioma patients}

Patients with head-and-neck paragangliomas reported a substantially impaired QoL compared with their own controls and the extended control group (Table 2). The QoL scores were significantly reduced in 12 out of the 21 subscales when compared with own controls, and in 18 out of the 21 subscales when compared with ageand sex-adjusted values derived from the previous studies.

When studying the QoL results in detail, compared with own controls, four out of the five subscales of the MFI-20 assessing general and physical fatigue and reduction in activity and motivation were significantly decreased in the head-and-neck paraganglioma patients. The NHP questionnaires revealed a significant reduction in energy, disturbed emotional reaction, and social isolation in the patient group. Patients experienced problems in physical and social functioning, role limitations due to physical problems, increased pain, and changes in general health perception according to the SF-36 questionnaire. No differences were found in anxiety or depression scores.

Compared with the extended control group, all subscales of the MFI-20 were affected, including mental fatigue. According to the NHP, all subscales that were also affected in comparison with own controls were affected with sleep. All items of the SF-36 questionnaire except for health change and physical functioning were affected in patients compared with the extended control group. In contrast with the comparison with own controls, anxiety and depression and total anxiety and

Table 1 Characteristics of head-and-neck paraganglioma patients and controls.

\begin{tabular}{|c|c|c|c|}
\hline & Patients $(n=82)$ & Own controls $(n=44)$ & Leiden controls $(n=168)$ \\
\hline Age (years, mean \pm s.D.) & $48.8 \pm 12.04$ & $47.24 \pm 10.90$ & $49.42 \pm 12.62$ \\
\hline $\operatorname{Sex}(\mathrm{M} / \mathrm{F})$ & $42 / 40$ & $20 / 20^{a}$ & $86 / 82$ \\
\hline 1 Glomus tumor & $33(40 \%)$ & & \\
\hline 2 Glomus tumors & $22(27 \%)$ & & \\
\hline$\geq 3$ Glomus tumors & $27(33 \%)$ & & \\
\hline Carotid body glomus tumor & $24(29 \%)$ & & \\
\hline Surgery & $11(13 \%)$ & & \\
\hline No surgery & $13(16 \%)$ & & \\
\hline History intra-adrenal paraganglioma & $10(12 \%)$ & & \\
\hline History extra-adrenal paraganglioma & $2(1 \%)$ & & \\
\hline Intra-adrenal paraganglioma at the time of study & $4(5 \%)$ & & \\
\hline Extra-adrenal paraganglioma at the time of study & $1(1 \%)$ & & \\
\hline Hearing loss & $32(39 \%)$ & & \\
\hline Tinnitus & $30(37 \%)$ & & \\
\hline Difficulties in swallowing & $21(26 \%)$ & & \\
\hline Number of patients tested for mutation & $54(67 \%)$ & & \\
\hline SDHD (D92Y) mutation & $45(83 \%)^{b}$ & & \\
\hline
\end{tabular}

${ }^{\text {a}}$ Four missing.

${ }^{\mathrm{b}}$ Of tested patients. 
Table 2 Quality of life (QoL) parameters (Hospital Anxiety and Depression Scale, HADS; Multidimensional Fatigue Index, MFI-20; Nottingham Health Profile, NHP and Short Form-36, SF-36) in patients with head-and-neck paragangliomas.

\begin{tabular}{|c|c|c|c|c|c|}
\hline Questionnaire & $\begin{array}{l}\text { Patients } \\
(n=82)\end{array}$ & $\begin{array}{l}\text { Own controls } \\
(n=44)\end{array}$ & $P$ value & $\begin{array}{l}\text { Leiden controls } \\
(n=168)\end{array}$ & $P$ value \\
\hline \multicolumn{6}{|l|}{ SF-36 } \\
\hline Physical functioning & $86.7 \pm 17.2$ & $94.4 \pm 10.3$ & 0.002 & $91.0 \pm 14.7$ & 0.052 \\
\hline Social functioning & $82.8 \pm 23.1$ & $89.6 \pm 15.4$ & 0.05 & $92.4 \pm 15.3$ & 0.001 \\
\hline Role limitations due to physical problems & $73.2 \pm 36.8$ & $89.5 \pm 25.1$ & 0.004 & $89.2 \pm 26.3$ & 0.000 \\
\hline $\begin{array}{l}\text { Role limitations due to emotional } \\
\text { problems }\end{array}$ & $81.7 \pm 34.8$ & $91.5 \pm 24.2$ & 0.07 & $90.1 \pm 25.9$ & 0.039 \\
\hline Bodily pain & $83.1 \pm 19.5$ & $90.7 \pm 15.3$ & 0.02 & $87.9 \pm 16.3$ & 0.035 \\
\hline General health perception & $66.8 \pm 21.8$ & $76.5 \pm 18.5$ & 0.01 & $75.7 \pm 17.2$ & 0.001 \\
\hline Change in health & $51.5 \pm 19.4$ & $51.2 \pm 13.3$ & 0.90 & $55.0 \pm 18.3$ & 0.254 \\
\hline \multicolumn{6}{|l|}{ NHP } \\
\hline Energy & $16.2 \pm 31.1$ & $3.8 \pm 13.7$ & 0.003 & $4.7 \pm 17.7$ & 0.002 \\
\hline Pain & $5.2 \pm 15.0$ & $3.9 \pm 14.1$ & 0.65 & $2.7 \pm 11.0$ & 0.18 \\
\hline Emotional reaction & $12.1 \pm 23.3$ & $3.9 \pm 12.0$ & 0.01 & $3.0 \pm 9.8$ & 0.001 \\
\hline Sleep & $12.7 \pm 26.6$ & $11.7 \pm 22.9$ & 0.84 & $6.3 \pm 17.2$ & 0.03 \\
\hline Physical ability & $4.1 \pm 9.0$ & $2.5 \pm 7.1$ & 0.32 & $3.7 \pm 10.9$ & 0.84 \\
\hline Social isolation & $6.9 \pm 17.8$ & $2.0 \pm 7.7$ & 0.04 & $0.9 \pm 5.6$ & 0.002 \\
\hline Total & $49.7 \pm 87.4$ & $26.8 \pm 59.8$ & 0.09 & $3.5 \pm 7.6$ & 0.000 \\
\hline \multicolumn{6}{|l|}{ MFI-20 } \\
\hline General fatigue & $10.0 \pm 4.9$ & $8.3 \pm 3.8$ & 0.03 & $7.9 \pm 3.7$ & 0.001 \\
\hline Physical fatigue & $9.1 \pm 4.2$ & $7.1 \pm 3.4$ & 0.009 & $7.5 \pm 3.5$ & 0.002 \\
\hline Reduced activity & $8.7 \pm 3.7$ & $6.5 \pm 3.3$ & 0.001 & $6.9 \pm 3.1$ & 0.000 \\
\hline Reduced motivation & $8.4 \pm 3.4$ & $7.0 \pm 3.5$ & 0.03 & $6.8 \pm 2.7$ & 0.000 \\
\hline Mental fatigue & $9.3 \pm 4.4$ & $8.1 \pm 4.0$ & 0.14 & $7.2 \pm 3.5$ & 0.000 \\
\hline \multicolumn{6}{|l|}{ HADS } \\
\hline Anxiety & $5.1 \pm 4.2$ & $4.0 \pm 3.2$ & 0.10 & $3.5 \pm 2.9$ & 0.001 \\
\hline Depression & $3.3 \pm 3.6$ & $2.4 \pm 2.6$ & 0.10 & $2.2 \pm 2.2$ & 0.009 \\
\hline Total & $8.4 \pm 7.3$ & $6.4 \pm 5.1$ & 0.07 & $5.8 \pm 4.4$ & 0.002 \\
\hline
\end{tabular}

depression scores of the HADS were affected in patients with head-and-neck paragangliomas.

\section{Factors influencing QoL in patients with head-and-neck paragangliomas}

Age As expected, age negatively influenced physical functioning and bodily pain of the SF-36 subscale $(\beta=-0.289, \quad P=0.02$ and $\beta=-0.271, P=0.03$ respectively) and positively influenced role limitations due to emotional problems $(\beta=0.238, P=0.029)$.

Gender Women had a significantly increased anxiety score compared with men $(6.3 \pm 4.2$ vs $4.0 \pm 3.9$, $P=0.012)$. According to the NHP, women experienced more pain $(10.2 \pm 20.2$ vs $0.4 \pm 1.77, P=0.004)$ and impairment in physical mobility $(6.9 \pm 11.2$ vs $1.5 \pm 5.1, P=0.008)$ and tended to have more impairment of sleep $(18.0 \pm 30.4$ vs $7.6 \pm 21.5, P=0.079)$ compared with men.

Number of head-and-neck paragangliomas Sixty percent of the patients had multiple head-and-neck paragangliomas. Besides an effect on general fatigue according to the MFI-20 $(11.3 \pm 5.3$ vs $9.1 \pm 4.5$, $P=0.044$ ), no other differences were found.
Surgery Surgical removal of glomus tumors could not be related to a significant reduction in QoL parameters in this study.

Head-and-neck paraganglioma-related complaints Dysphonia was present in $21 \%$ of the patients and significantly impaired activity and mental fatigue according to the MFI-20 $(10.4 \pm 3.0$ vs $8.3 \pm 3.7$, $P=0.03$ and $11.4 \pm 4.1$ vs $8.7 \pm 4.4, P=0.03$ respectively) and physical functioning and general health perception according to the SF-36 questionnaire $(78.2 \pm 21.7$ vs $89.1 \pm 15.3, P=0.02$ and $57.9 \pm 17.3$ vs $69.7 \pm 22.0, P=0.045$ respectively). Hearing loss, tinnitus, swallowing, and other local complaints did not significantly reduce QoL on any of the subscales of the questionnaires.

Other paragangliomas and catecholamine excess In total, 17 patients were diagnosed with adrenal or extraadrenal paragangliomas, either in the past or at present. At the time of this study, four patients were diagnosed with an intra-adrenal paraganglioma and were surgically treated after appropriate $\boldsymbol{\alpha}$-blockade. The presence of these paragangliomas at other locations did not significantly influence QoL in this survey. Furthermore, no significant differences could be found between patients with and without past catecholamine excess. 
Genetic analysis Genetic analysis had been performed in 69 out of the original 105 patients. Out of the 82 patients participating in this study, 28 had not been tested, 9 were genotyped without finding a mutation, whereas in the remaining 45 patients a mutation was identified. Furthermore, 12 of the patients who had not been tested had a positive family history with a proved SDHD (D92Y) mutation and could be considered as SDHD (D92Y) positive. No differences in QoL scores were found when comparing these groups.

Multivariate linear regression analysis Multivariate linear regression analysis was performed in a model including age, gender, hearing loss, dysphonia, difficulties in swallowing, and number of head-and-neck paragangliomas (Table 3). Age was an independent predictor of physical functioning (SF-36: $\beta=-0.290, P=0.02)$ and bodily pain (SF-36: $\beta=-0.272, P=0.02$ ). Gender was found as an independent predictor of pain and physical ability (NHP: $\beta=-0.304, P=0.007$ and $\beta=-0.272$, $P=0.02$ respectively). Furthermore, females experienced more anxiety (HADS: $\beta=-0.297, P=0.01$ ). Dysphonia was found to be an independent predictor of both physical functioning and role limitations due to physical (although not significantly) and emotional problems according to the SF-36 scale (SF-36: $\beta=-0.295, \quad P=0.009$, $\beta=-0.222, P=0.06$ and $\beta=-0.246, P=0.03$ respectively) and mental fatigue on the MFI-20 $(\beta=0.242$, $P=0.04)$.

\section{Discussion}

This study is the first to report a reduced QoL in patients with head-and-neck paragangliomas using validated health-related questionnaires. Patients reported a decreased QoL in 12 out of the 21 subscales when compared with own controls, and in 18 out of the 21 subscales when compared with age- and sex-adjusted values derived from the previous studies performed in our institution. Especially, dysphonia was found to influence QoL perception in the head-and-neck paraganglioma patients.

Patients with head-and-neck paragangliomas reported an impaired QoL on the majority of the subscales of the different questionnaires covering the spectrum of both general and physical complaints to emotional problems. Although several studies have investigated QoL in patients with head-and-neck cancer, QoL data regarding paraganglioma patients are limited. Kollert et al. $(23,24)$ published data on neuropsychological evaluation (using the Sickness Impact Profile questionnaires) of post-operative QoL in the head-andneck paraganglioma patients. They compared QoL after paraganglioma surgery with the QoL scores of patients with acoustic neuroma surgery and concluded QoL to be better in the paraganglioma patients. However, they did not relate QoL to healthy controls or paraganglioma patients with a wait-and-see policy.

Table 3 Multiple linear regression analysis. Age, sex, hearing loss, tinnitus, dysphonia, difficulties in swallowing, and number of head-andneck paragangliomas were used as independent variables.

\begin{tabular}{lll}
\hline Questionnaire & Age & Sex \\
\hline SF-36 & $-0.290(0.02)$ & Dysphonia \\
Physical functioning & & $-0.295(0.009)$ \\
Social functioning & & $-0.222(0.06)$ \\
Role limitations due to physical problems & $-0.272(0.02)$ & $-0.246(0.03)$ \\
Role limitations due to emotional problems & & \\
Bodily pain & & \\
General health perception & & $-0.304(0.007)$ \\
Change in health & & \\
NHP & & $-0.272(0.02)$ \\
Energy & & \\
Pain & & \\
Emotional reaction & & \\
Sleep & & \\
Physical ability & & \\
Social isolation & & \\
Total & & \\
MFl-20 & & \\
General fatigue & & \\
Physical fatigue & & \\
Reduced activity & & \\
Reduced motivation & & \\
Mental fatigue & & \\
HADS & & \\
Anxiety & & \\
Depression & & \\
Total & & \\
\hline
\end{tabular}

Data shown are standardized $\beta$ 's ( $P$ value). 
Evaluation of the specific factors influencing QoL in the head-and-neck paraganglioma patients revealed not only the expected associations with age and sex but also that dysphonia especially affected QoL. Surprisingly, no such association could be found for tinnitus, hearing loss, and other local complaints in this cohort. The results regarding the impact of dysphonia are in line with QoL studies in dysphonic patients $(25,26)$.

In this study, patients were compared with own controls and controls derived from the previous studies performed in this hospital. The advantage of using own controls is that they are from the same geographic area and socioeconomic class as the patients (27). However, there may be a selection bias, because patients could have chosen subjects with a good health status (28). In addition, a considerable number of control subjects chose to return the questionnaires unanswered, resulting in a relatively small number of own controls. Therefore, we extended our control group with ageand sex-matched control subjects derived from the previous studies regarding QoL in our hospital (12-16). After extending our control group, the analysis revealed similar and even stronger associations.

The four health-related questionnaires used in this study were not disease specific and they were not developed to specifically assess OoL in the head-andneck paraganglioma patients. However, we found a reduced QoL in several of the subscales of the SF-36, the NHP, and the MFI-20, which was further strengthened in comparison with the extended control group. Therefore, we believe that there is indeed an effect of head-and-neck paragangliomas on general health and well-being on a broad spectrum of physical and social aspects. However, in comparison with the similarly obtained QoL scores in the non-functioning pituitary macroadenoma patients by Dekkers et al. (12), the extent of the QoL deficit in our patients seems to be less severe. In a recent study using the SF-36 questionnaire results in the type 2 diabetes patients, lower scores of QoL parameters were found in comparison with the head-and-neck paraganglioma patients (29). Therefore, the notion emerges that QoL is impaired in patients with head-and-neck paragangliomas, although to a lesser extent than other diseases. We think diseasespecific questionnaires should include problems experienced due to dysphonia, hearing loss, and sleeping disorders, and could have complementary results.

Although most paragangliomas are benign, their chronic nature and localization in close proximity with nerves and vasculature may result in considerable morbidity. In approximately one-third of the patients, local complaints resulting from the loss of nerve function were mentioned. In addition, with the discovery of the SDH genes (1) and the lifelong increased risk for the development of paragangliomas at other locations $(8,9,11)$, the patients and their affected family members are now subjected to a more intensive follow-up regimen. These factors may also adversely affect QoL.
In conclusion, our data indicate that although most head-and-neck paragangliomas have a benign character, the disease leads to an impaired QoL. Dysphonia contributes significantly to impaired QoL. QoL may also be affected by the chronic nature of the disease and the indication for long-term follow-up.

\section{References}

1 Baysal BE, Ferrell RE, Willett-Brozick JE, Lawrence EC, Myssiorek D, Bosch A, van der MA, Taschner PE, Rubinstein WS, Myers EN, Richard CW, III, Cornelisse CJ, Devilee P \& Devlin B. Mutations in SDHD, a mitochondrial complex II gene, in hereditary paraganglioma. Science $2000287848-851$.

2 Niemann S \& Muller U. Mutations in SDHC cause autosomal dominant paraganglioma, type 3. Nature Genetics 200026 $268-270$.

3 Astuti D, Latif F, Dallol A, Dahia PL, Douglas F, George E, Skoldberg F, Husebye ES, Eng C \& Maher ER. Gene mutations in the succinate dehydrogenase subunit SDHB cause susceptibility to familial pheochromocytoma and to familial paraganglioma. American Journal of Human Genetics 200169 49-54.

4 Benn DE \& Robinson BG. Genetic basis of phaeochromocytoma and paraganglioma. Best Practice and Research. Clinical Endocrinology and Metabolism 200620 435-450.

5 Koch CA, Vortmeyer AO, Zhuang Z, Brouwers FM \& Pacak K. New insights into the genetics of familial chromaffin cell tumors. Annals of the New York Academy of Sciences 2002970 11-28.

6 van der Mey AG, Maaswinkel-Mooy PD, Cornelisse CJ, Schmidt PH \& van de Kamp JJ. Genomic imprinting in hereditary glomus tumours: evidence for new genetic theory. Lancet 19892 1291-1294.

7 Timmers HJ, Kozupa A, Eisenhofer G, Raygada M, Adams KT, Solis D, Lenders JW \& Pacak K. Clinical presentations, biochemical phenotypes, and genotype-phenotype correlations in patients with succinate dehydrogenase subunit B-associated pheochromocytomas and paragangliomas. Journal of Clinical Endocrinology and Metabolism 200792 779-786.

8 Benn DE, Gimenez-Roqueplo AP, Reilly JR, Bertherat J, Burgess J, Byth K, Croxson M, Dahia PL, Elston M, Gimm O, Henley D, Herman P, Murday V, Niccoli-Sire P, Pasieka JL, Rohmer V, Tucker K, Jeunemaitre X, Marsh DJ, Plouin PF \& Robinson BG. Clinical presentation and penetrance of pheochromocytoma/paraganglioma syndromes. Journal of Clinical Endocrinology and Metabolism $200691827-836$.

9 Neumann HP, Pawlu C, Peczkowska M, Bausch B, McWhinney SR, Muresan M, Buchta M, Franke G, Klisch J, Bley TA, Hoegerle S, Boedeker CC, Opocher G, Schipper J, Januszewicz A \& Eng C. Distinct clinical features of paraganglioma syndromes associated with SDHB and SDHD gene mutations. Journal of the American Medical Association 2004292 943-951.

10 Taschner PE, Jansen JC, Baysal BE, Bosch A, Rosenberg EH, Brocker-Vriends AH, Der Mey AG, van Ommen GJ, Cornelisse CJ \& Devilee P. Nearly all hereditary paragangliomas in the Netherlands are caused by two founder mutations in the SDHD gene. Genes, Chromosomes and Cancer $200131274-281$.

11 van Houtum WH, Corssmit EP, Douwes Dekker PB, Jansen JC, van der Mey AG, Brocker-Vriends AH, Taschner PE, Losekoot M, Frolich M, Stokkel MP, Cornelisse CJ \& Romijn JA. Increased prevalence of catecholamine excess and phaeochromocytomas in a well-defined Dutch population with SDHD-linked head and neck paragangliomas. European Journal of Endocrinology 2005152 87-94.

12 Dekkers OM, van der Klaauw AA, Pereira AM, Biermasz NR, Honkoop PJ, Roelfsema F, Smit JW \& Romijn JA. Quality of life is decreased after treatment for nonfunctioning pituitary macroadenoma. Journal of Clinical Endocrinology and Metabolism 200691 3364-3369. 
13 Biermasz NR, Pereira AM, Smit JW, Romijn JA \& Roelfsema F. Morbidity after long-term remission for acromegaly: persisting joint-related complaints cause reduced quality of life. Journal of Clinical Endocrinology and Metabolism $2005902731-2739$.

14 Biermasz NR, van Thiel SW, Pereira AM, Hoftijzer HC, Van Hemert AM, Smit JW, Romijn JA \& Roelfsema F. Decreased quality of life in patients with acromegaly despite long-term cure of growth hormone excess. Journal of Clinical Endocrinology and Metabolism 200489 5369-5376.

15 Dekkers OM, Biermasz NR, Smit JW, Groot LE, Roelfsema F, Romijn JA \& Pereira AM. Quality of life in treated adult craniopharyngioma patients. European Journal of Endocrinology 2006154 483-489.

16 van Aken MO, Pereira AM, Biermasz NR, van Thiel SW, Hoftijzer HC, Smit JW, Roelfsema F, Lamberts SW \& Romijn JA. Quality of life in patients after long-term biochemical cure of Cushing's disease. Journal of Clinical Endocrinology and Metabolism $2005903279-3286$.

17 Zigmond AS \& Snaith RP. The hospital anxiety and depression scale. Acta Psychiatrica Scandinavica 198367 361-370.

18 Smets EM, Garssen B, Bonke B \& de Haes JC. The multidimensional fatigue inventory (MFI) psychometric qualities of an instrument to assess fatigue. Journal of Psychosomatic Research 199539 315-325.

19 Hunt SM, McKenna SP, McEwen J, Backett EM, Williams J \& Papp E. A quantitative approach to perceived health status: a validation study. Journal of Epidemiology and Community Health $198034281-286$.

20 Hunt SM \& McEwen J. The development of a subjective health indicator. Sociology of Health and Illness 19802 231-246.

21 Brazier JE, Harper R, Jones NM, O'Cathain A, Thomas KJ, Usherwood T \& Westlake L. Validating the SF-36 health survey questionnaire: new outcome measure for primary care. British Medical Journal 1992305 160-164.
22 Ware JE, Jr \& Sherbourne CD. The MOS36-item short-form health survey (SF-36), I. Conceptual framework and item selection. Medical Care 199230 473-483.

23 Kollert M, Minovi AA, Draf W \& Bockmuhl U. Cervical paragangliomas-tumor control and long-term functional results after surgery. Skull Base 200616 185-191.

24 Kollert M, Minovi A, Mangold R, Hendus J, Draf W \& Bockmuhl U. Paraganglioma of the head and neck-tumor control, functional results and quality of life. Laryngo-Rhino-Otologie $2006 \mathbf{8 5}$ 649-656.

25 Krischke S, Weigelt S, Hoppe U, Kollner V, Klotz M, Eysholdt U \& Rosanowski F. Quality of life in dysphonic patients. Journal of Voice $200519132-137$.

26 Jones SM, Carding PN \& Drinnan MJ. Exploring the relationship between severity of dysphonia and voice-related quality of life. Clinical Otolaryngology 200631 411-417.

27 Grimes DA \& Schulz KF. Compared to what? Finding controls for case-control studies Lancet 2005365 1429-1433.

28 Wacholder S, Silverman DT, McLaughlin JK \& Mandel JS. Selection of controls in case-control studies. II. Types of controls. American Journal of Epidemiology 1992135 1029-1041.

29 Papadopoulos AA, Kontodimopoulos N, Frydas A, Ikonomakis E \& Niakas D. Predictors of health-related quality of life in type II diabetic patients in Greece. BMC Public Health 20077186.

Received 3 October 2007

Accepted 26 October 2007 